\title{
Family and Health over the Past Decade: Review of Selected Studies and Areas of Future Inquiry
}

\author{
Christopher R. Tamborini ${ }^{1,2,3}$
}

Accepted: 11 September 2020 / Published online: 23 October 2020

(c) Springer Science+Business Media, LLC, part of Springer Nature 2020

\begin{abstract}
Research on the family-health nexus cuts across disciplines, focuses on a broad range of issues, and is set against a backdrop marked by increasing diversity of family structures and households, aging families, and intensifying concerns about health and social inequalities. Over the last decade, a plethora of articles appearing in The Journal of Family and Economic Issues (JFEI) have examined the interplay between family and health. This article attempts to crystallize the primary contributions of this body of work. My discussion is organized around various thematic areas that emerged from the review: (a) childbearing, (b) children's health, (c) relationships, (d) caregiving, and (e) the impact of health on household finances. I close by sketching out some useful areas for future research in the next decade.
\end{abstract}

Keywords Family $\cdot$ Health $\cdot$ Decade in review

The interplay between family and health has been of increasing interest to scholars and policymakers over the last decade. Research on the family-health nexus cuts across disciplines, focuses on a broad range of issues, and is set against a backdrop marked by increasing diversity of family structures and households, aging families, and intensifying concerns about health and social inequalities. The coronavirus 2019 pandemic (COVID-19) has clarified the importance of understanding family and health linkages. For example, high levels of unemployment associated with the COVID-19 has exerted substantial financial and mental pressures on families, which in turn can lead to health problems or exacerbate existing conditions.

This is one of several papers published together in Journal of Family and Economic Issues on the "Special Issue on Virtual Decade in Review".

Christopher R. Tamborini

tamborini@cua.edu; chris.tamborini@gmail.com

1 Department of Sociology, The Catholic University of America, 103 Aquinas Hall, Washington, DC 20064, USA

2 Institute for Policy \& Social Research, University of Kansas, Lawrence, USA

3 Office of Research, Evaluation, and Statistics, U.S. Social Security Administration, Washington, DC, USA
In the last decade, a plethora of articles appearing in The Journal of Family and Economic Issues (JFEI) have examined topics that broach the family-health nexus. This article attempts to crystallize the primary contributions of this body of work. My discussion is organized around various thematic areas that emerged from the review: (a) childbearing, (b) children's health, (c) relationships, (d) caregiving, and (e) the impact of health on household finances. While the selected research is not exhaustive of all JFEI publications addressing family-health linkages over the last decade, their inclusion intends to showcase the breadth and scope that a range of studies have taken. I close by sketching out some useful areas for future research in the next decade.

\section{Childbearing: Levels, Timing and Policies}

A major focus of family-health scholarship in JFEI over the last decade has been childbearing. Shreffler and Johnson's (2013) study implicated women's career preferences as important for understanding fertility patterns, using two waves of the National Survey of Family and Households (NSFH). The authors showed that the commonly found negative relationship between women's work hours and fertility becomes nonsignificant once adjustments are made for career and family preferences. Importantly, women with high fertility intentions were found to have 
greater odds of giving birth, regardless of work hours. Women's work-family preferences should, therefore, the authors argued, receive greater attention in research on childbearing patterns as well as in pronatalist policy debates.

Childbearing also depends on a household's socioeconomic circumstance. In this vein, Mansour (2018) provided insights into how economic uncertainty influences the probability of having multiple children relative to one child. Employing linear and non-linear regression models and using data from the Panel Study of Income Dynamics (PSID), the author found heterogeneous effects of income volatility across the income distribution. Measurement of income volatility included indicators of the variance in household earnings beginning from the birth year of the first child, as well as an indicator of downward volatility, which captured instances when income decreased by more than 5\% over the interview period. Importantly, the analysis showed that downward volatility was associated with lower odds of having a second child for mothers in the low and high end of the income distribution. By contrast, negative income changes were associated with higher odds of giving birth to a second child for mothers in the second income quartile. Overall, the experience of negative income changes was found to have greater effects (negative) on total fertility than absolute income volatility, which was not associated with total births.

In addition to assessing how household socioeconomic circumstances matter, the role of public policy in shaping childbearing was a topic of considerable interest in the JFEI over the last decade. Cheng (2011) provided compelling analysis of contraceptive knowledge in Taiwan over a period in which various family planning programs were implemented (beginning in 1964). Using cross-sectional, representative data from 1965 to 1985 , Cheng found that mass media campaigns and social networks helped increase contraceptive-related knowledge, which in turn, was associated with lower fertility. These results held using an instrumental variable (IV) approach that adjusted for endogeneity in contraceptive knowledge on fertility.

In addition, JFEI research extended understanding of how individuals respond to policies aiming to reduce childbearing costs. In this vein, Barbos and Milovanska-Farrington (2019) assessed the expansion of mandatory maternal paid leave in Switzerland from 8 to 14 weeks using two waves of the European Social Survey from 2004 to 2010 . The primary outcome variable examined was a categorical measure of an individual's fertility intentions for the three years following the interview ("Definitely not," "Probably not," "Don't know," Definitely yes," and "Probably yes"). The analysis found a significant rise in fertility intentions following the expansion, most notably among men, individuals aged 31 to 36 , and individuals with at least two children.
Ang (2015) studied two pronatalist programs implemented at different periods in Quebec, Canada: (a) direct cash benefits (baby bonus), and (b) an increase in parental leave payments from 55 to $70 \%$ of prior income (Quebec Parental Insurance program). The results demonstrated that expanded parental leave payments were associated with greater fertility, albeit with some heterogeneity by birth parity. The cash benefit program, by contrast, had smaller effects. Interestingly, the author's assessment of the financial implications of both programs found that the parental leave expansion cost substantively less per additional birth than direct cash benefits.

Further highlighting why public policy matters for childbearing, Abramowitz (2017) examined state-level variation in insurance mandates for assisted reproductive technology (ART). The author found that state mandates were associated with delayed childbearing and increased probability of first birth after age 30, but only for college-educated women. Differences in access and knowledge about ART and the insurance mandates by educational attainment may explain why college-educated women appeared more responsive to the mandates.

Beauchamp (2016) addressed whether giving birth in states with increasing abortion costs was associated with a reduction in the likelihood of partnership dissolution. The author also investigated potential spillover effects of giving birth in areas with rising abortion costs in terms of sexual behavior and the family contexts in which children live. The study found lower separation rates and higher cohabitation following a birth among poor young women living in states with rising abortion costs. No effect was found on marriage entry. These results held in estimations using miscarriage as a natural experiment, which provided a control group of pregnant women who faced the same policy milieu, but did not have a child.

Another set of JFEI studies focused on teen pregnancy. Cherry and Wang (2015) investigated how contextual characteristics at the state level were associated with teen birth rates from 2001 to 2009 . Their work found that greater employment among female teenagers and men aged 20-24 was associated with higher teen birth rates, especially among disadvantaged youth. In another study, Grossbard and Vernon (2017) probed the effects of common law marriage (CLM) on teen births, using the Current Population Survey's fertility supplements from 1990 to 2010 and vital statistics data. Comparing earlier-life childbearing in states that eliminated CLM with states that did not, the authors found a small positive effect of CLM elimination on teen births, but only among teens aged 15-17.

Appearing in JFEI's policy debate section, Block (2014) developed a theoretical discussion that delineated a third position related to abortion. The author first sketched the parameters of the current debate, contrasting pro-life and 
pro-choice views of the fetus. Against this backdrop, the author outlined a third position termed evictionism, which was framed as a different way to think about the abortion issue that in some ways reflects a compromise between pro-life and pro-choice positions. A central tenant of this position is that women are seen to have the legitimate right (derived from property rights) to evict the fetus from their bodies at any time during the pregnancy, but they are not legally permitted to kill the fetus. One implication, Block speculated, is that a greater share of fetuses that are evicted during early stages of pregnancy will survive in the future as medical technology improves.

\section{Children's Health}

Another thematic area of family-health scholarship appearing in the JFEI over the last decade considers the sources and consequences of children's health. One strand of this work focused on how children's health influences their parents, largely in terms of labor market outcomes. For instance, the effect of having a child with health problems on maternal employment was examined by Zan and Scharff (2018). They found that having a child with a disability was associated with lower maternal employment, but the effect differed for racial-ethnic subgroups. A particularly strong effect was found among Hispanic mothers, and Black mothers appeared especially sensitive to time burdens related to children's health problems.

Along a similar vein, Richard (2016), using two waves of the child development supplements (CDS) of the Panel study of income dynamics (PSID), found heterogeneous effects of having a child with emotional and behavioral problems (EBP) for maternal employment outcomes by family type. Having a child with a mental disorder was found to be associated with lower hourly wage rates and annual earnings among single mothers, but it was positively associated with these outcomes among married mothers, although the positive effect for annual earnings became insignificant in a Heckman model that controlled for omitted variables related to labor force participation.

Bhatt (2011) looked at how risky health behaviors among adolescents shape intergenerational financial transfers, using data from the first seven waves of National Longitudinal Survey of Youth 1997 (NLSY97). The analysis demonstrated that parents respond to adolescent children's excessive drinking by reducing financial transfers to them (i.e., pecuniary parental punishment). In some models, the reduction was around 80 to $90 \%$.

Another strand of JFEI studies assessed the factors that shape children's health. Given intensified concerns about childhood obesity, Jung and Chang (2016) provide a timely assessment of maternal employment and childhood weight.
Adjusting for the selection of mothers into paid work, they found heterogeneous effects of maternal employment by family structure, income, and child's age. For example, maternal employment was positively associated with child obesity among 3rd to 5th graders in two-parent families with incomes below poverty. This could reflect, the authors reasoned, reduced time for caregiving (e.g., meal preparation and supervision) at a critical stage of childhood marked by growing independence. Yet, maternal employment was associated with lower childhood obesity among poor femaleheaded households, reflecting positive links between work hours and resources.

Two of the articles reviewed considered how religiosity might influence children's health. Chiswick and Mirtcheva (2013) examined children's physical and mental health by religious affiliation and church attendance. Relying mainly on a sample of 2604 children aged 6-19 from the 2002 Child Development Supplement to the Panel Study of Income Dynamics (PSID), the study found that religious affiliation and church attendance was associated with improved physical and psychological health, especially notable in adolescents' mental health. Results were shown to be robust to adjustments for selection bias into religion using propensitymatching techniques.

Delaney and Winters (2014) probed whether children of the clergy ("preachers' kids") differed in use and intensity of alcohol, cigarette, marijuana, and other drugs relative to their peers. They found lower use of alcohol, marijuana, and other drugs among preachers' kids. However, cigarette smoking and intensity of consumption among users did not show systematic cross-group differentials. The authors underscore the importance of social relationships and networks for comprehending children's health behaviors.

Gustavsen et al. (2016) also investigated children's risk behaviors, but focused on the impact of parental relationship dissolution. Examining a sample of adolescents and young adults from Add Health data, they found parental divorce was associated with greater odds of risky behaviors among adolescents, particularly for girls. For instance, children from divorced families had a $10 \%$ higher likelihood of binge drinking and alcohol consumption, tobacco use, and marijuana uptake. Hard drug use was not associated with parental divorce, but higher tobacco and marijuana use persisted over time.

Hofferth and Pinzon (2011) considered how nonresidential fathers' child support and contact shape children's health following a relationship dissolution. Using US data from the Early Childhood Longitudinal Survey (ECLS-K), the authors found that fathers' support payments and contact frequency following relationship dissolution had no effect on children's health. However, poor child health was associated with reduced support payments. The authors posited that fathers' time and financial investments may depend on 
child health, suggesting that children with poor health could be doubly disadvantaged following parental relationship dissolution.

Beyond parental relationship status mattering for children's health, Lim (2019) called attention to the importance of parental employment. Drawing longitudinal data from 1994 to 2008 in the National Longitudinal Survey of Youth and Children and Young Adults 1979, the study identified variation in children's health insurance status by types of maternal employment, including part-time, temporary, contract, and self-employment. The author concluded that children with mothers in nonstandard work were the most disadvantaged in terms of health insurance coverage, particularly among single mothers.

Finally, Choi (2011) examined whether parental health influences children's work status and educational attainment as they age, which in turn shapes their health trajectories. Drawing panel data from the Russia Longitudinal Monitoring Survey (1994-2004), the study estimated the effects of changes in parental self-reported health status on children aged 13-29 living with both parents over the 10-year observation period. A significant gender differential was found. Health declines among fathers was associated with lower educational achievement and labor market participation among daughters but not sons. Explanations for this pattern point to the gender gap in caregiving, which leads to a reduction in daughters' (but not sons') educational investments and labor supply when a parent is ill.

\section{Relationships and Adult Health}

The selected JFEI articles also demonstrate the importance of social relationships for adult health. Kohn and Averett (2014), using data from 18 years of the British Household Panel Survey, found that being in a relationship (marriage and cohabitation) was protective of health. The study used a dynamic fixed-effects model with a variety of instruments to adjust for potential reverse causality from health status to relationship status. Importantly, their analysis showed that marriage and cohabitation had equally beneficial effects for health.

Miller and Pylypchuk (2014) identified preventive care utilization as an important pathway that can explain why marriage improves health. Examining rich data from the Medical Expenditure panel survey (MEPS-HC) and linked National Health Interview Survey (NHIS), the authors found that marriage was associated with greater preventive physical and dental examinations relative to those who remained single. For women, marriage also was associated with greater utilization of mammograms and pap smears. A number of spousal characteristics, such as education, income, and risk preferences, were found to generate heterogeneity in the observed effects.

Recent work by Eshak (2019) highlighted that workfamily links also can shape health; in particular, that workfamily imbalances can harm mental health. Using a novel cross-sectional survey administered in Upper Egypt, the author found that work-to-family conflict was associated with greater probability of mental health problems. Familyto-work conflict also was related to mental health problems but to a lesser degree. Notably, traveling away from home for work as well as reduced sleep due to family responsibilities were among the factors most negatively associated with mental health.

JFEI research over the past decade has shown that living arrangements can shape health via the spillover effects they have. Here, Robinson (2013) assessed the within-family effects of health and nutrition programs on non-eligible family members, using data from the US National Health and Nutrition Examination Survey. The author found positive health spillovers of Women's, Infants, and Children supplemental (WIC) food program participation across siblings. In particular, non-eligible children in households participating in the WIC program reported better health than comparable children in non-participating households, especially older male children. The author attributed this pattern to the reallocation of financial resources toward older children due to changes in food budgets.

\section{Caregiving: Patterns and Consequences}

Caregiving is another important dimension of the familyhealth nexus identified in JFEI publications over the last decade. Suh (2016) illustrated the complexity and implications of caregiving measurement, with a focus on "sandwich" care. Using pooled samples from the American Time Use Survey (ATUS), the study distinguished between interactive (e.g., physical care) and supervisory (e.g., watching children, trips to doctors) forms of care. The author found that the share of individuals aged 25-44 engaged in interactive child and adult care on the same day (sandwich care) was $7.8 \%$ for women and $4.8 \%$ for men. However, adopting a broader definition of care, the proportion rose to $77.2 \%$ of women and $62.5 \%$ of men. The estimated time burden for those engaged in childcare and interactive adult care was 10.9 mean daily hours for women aged 25-44 and 8.2 for men. The author stressed the need to develop more comprehensive measures of sandwich care to better understand patterns, consequences, and variation across subgroups.

Shooshtari et al. (2017) provided a timely assessment of the economic and social consequences of caregiving in the Canadian context, using representative data from the 2007 General Social Survey. They found that $42 \%$ of Canadian 
caregivers reported at least one adverse health or social impact, with the most common being a reduction of social and leisure activities. Interestingly, elevated out-of-pocket spending was associated with more negative consequences of caregiving.

Kusa (2019) looked at caregiving in terms of support for intra-family time transfers. Using representative data (GESIS Panel) in Germany, the author examined variation in the support for the equity principle for monetary compensation for two types of caregiving: (a) long-term care to elderly parents provided by adult children, and (b) childcare provided by grandparents. The majority $(79 \%)$ reported support for monetary compensation for long-term care of elderly parents, while a substantively smaller proportion $(38 \%)$ reported support for childcare by grandparents. Attitudes varied across individual characteristics including socioeconomic status, age, and self-serving bias measures. Notably, support for monetary compensation for both caregiving types was highest among older respondents.

\section{Impact of Health on Economic Circumstances}

A stream of the selected JFEI studies sought to understand the consequences of health for individuals' and households' economic circumstances. Giovanis and Ozdamar (2019) assessed how disability affects the labor supply and wages of Iraqi women. Analyzing data from the Iraqi Household Socio-economic Survey (IHSES (2012-2013), the findings revealed strong negative effects of disability on women's likelihood both to participate in the labor market and their wages if working. The authors emphasized the reduced household bargaining power of disabled women and the need to promote expanded labor market opportunities for them.

Mussida and Sciulli's (2019) study addressed how the presence of a disabled person in the household affects the employment of women in cohabiting relationships in three countries (Italy, France, and UK) with different cultural and policy milieus. The authors found lower employment rates among women cohabiting with a disabled person in Italy, a country with more limited formal caregiving services and a stronger male breadwinner model. In contrast, the presence of a disabled person was found to be associated with greater women's employment in France and the UK, two countries with greater opportunities for part-time work and formal care services.

Other studies remind us of the substantive economic consequences of health. The financial impact of cancer was examined by Svynarenko et al. (2019). Drawing panel data from nine biannual waves of the Health and
Retirement Study (HRS) spanning 1998 to 2014, a central innovation of the study was to adopt broader measures of economic outcomes that included changes in household liquidity, solvency, and investment ratios. The authors' analysis uncovered important increases in liquidity and debt-to-assets in the initial stage of cancer care. The costs of cancer care and rehabilitation for liquidity and solvency outcomes were more modest among insured survivors, but lasting declines in investment assets to net worth were observed. This suggested, according to the authors, that cancer survivors may tap into retirement savings to meet the financial needs related to care.

White-Means and Osmani (2019) focused on cancer survivors' labor market patterns across racial-ethnic groups. Using high quality data from the US Medical Expenditure Panel Survey (MEPS) over the period of 2008-2014, the authors found lower probability of employment among Hispanic and Black breast cancer survivors relative to Whites. Among those employed, however, Black and Hispanic breast cancer survivors worked more hours. Among prostate cancer survivors, Blacks had lower employment rates than comparable Whites. The analysis identified racial differences in job characteristics, such as concentration in blue collar or service occupations, as helping to explain the differential outcomes.

In addition to current economic circumstance, health also shapes the need for long-term care insurance (LTC). Barnett and Stum (2012)'s study sought to improve understanding of the factors that influence access and coverage to long-term care insurance from a couple-level perspective. Conducting a qualitative dyadic analysis of married couples in Minnesota, the study revealed substantive consensus among couples in terms of their LTC intentions, but heterogeneity was also found in terms of their decision outcomes, such as the decision of whether to purchase LTCI, self-insure, or take no action.

Finally, Berger et al. (2016) study of the relationship between household debt and depression (CES-D partial scale) showed that health not only matters for economic outcomes, but economic circumstances also matters for health. Using data from adults ages 21-65 years in two waves of the National Survey of Families and Households, they found that greater short-term unsecured debt (e.g., consumer debt) was associated with more depression, while the relationship between longer-term debt and depression was much weaker. According to the authors this may indicate that short-term unsecured debt may be taken on with less personal choice. The negative associations between unsecured debt and mental health were particularly notable among older individuals and the less educated. 


\section{Future Research}

Future research addressing the interplay between family and health has far-reaching significance, and studies appearing in the JFEI over the last decade have informed much about these linkages. Despite the progress, significant work remains to be done.

To begin with, scholarship might benefit from greater focus on the complex and multilevel pathways that link family and health outcomes. Most research to date is primarily focused on understanding particular family and health relationships rather than what processes connect them. A challenge is that data frequently provide limited information about mechanisms. For example, Jung and Chang (2016) demonstrated significant associations between maternal employment and childhood weight gain, but data on the potential mechanisms underlying this relationship are likely not available (e.g., meal preparation).

Research in the next decade is poised to develop more robust causal evidence about family and health linkages. One enduring complexity relates to the selection processes that drive both entry and exit into family and health statuses. Understanding selection into statuses like marriage and divorce has attracted considerable attention, however existing knowledge is based on patterns observed in older cohorts. Selection processes may be different in younger cohorts. Moreover, selection into second order marital statuses, like remarriage, or separately, having a child with health problems, are not well studied. One way forward may be greater use of longitudinal or retrospective data that provide information about a person's health, family, and economic statuses prior to the contemporaneous relationship of interest. Such data may allow better identification of the sequencing of family and health events over the life course. No doubt, researchers will find ways to strengthen causal inferences by building on their methodological toolkits.

Another fruitful avenue of future investigations entails studying the health implications of the "second demographic transition." The greater complexity and diversity in relationships implicated by the second demographic transition means that research may benefit from greater attention to the health consequences of family histories rather than current status (Tamborini et al. 2016). Fewer marital relationships and smaller families also suggest potentially narrower pools of caregivers. Finally, to the extent that diverse family structures and households become more normative (e.g., divorce, blended families), reconsideration of a range of family-health linkages in more recent cohorts is warranted.

Additionally, there is continued need to account for heterogeneity. The family and health relationships we investigate not only differ across commonly examined covariates such as gender, education, and income subgroups, but also by the timing of events (e.g., early or late life), duration of statuses (e.g., length of marriage) and relationship quality, among other aspects.

Novel contributions also can be made by devoting greater attention to family-health linkages over longer stretches of an individual's life. Although researchers increasingly employ longitudinal data, the follow-up period often encompasses only several years. Analysis of long-term longitudinal data or retrospective life histories can be revealing and allow for better identification of the sequencing of events (Tamborini et al. 2016).

To be sure, future research also would benefit from analysis of the short- and long-term impacts of COVID-19. Economic pressures associated with the pandemic, including high levels of unemployment and underemployment, along with social distancing and lockdowns, are likely to alter the timing and incidence of family-related life events including divorce, separation, and union formation. How these life events shape health-related behaviors and longterm health outcomes in the context of the pandemic are also of interest. COVID-19 also has important consequences for caregiving. Smaller families have reduced the pool of informal caregivers for older adults, who are at higher risk of complications or death from COVID19 , as well as social isolation. The extent to which the adverse impacts of COVID-19 for families and health are experienced disproportionately by disadvantaged groups in affected countries is a topic of particular importance.

Finally, a new generation of research is likely to make use of novel sources of data. Innovative data capturing intergenerational ties may allow researchers to cast new light on family and health processes from one generation to the next. The increasing use of administrative data, especially those matched to survey data (Penner and Dodge 2019; Couch et al. 2015), is also promising. Furthermore, emerging methods in text analysis of social media as well as new forms of data mining and analytic tools may enhance scholarship on family and health in ways not yet anticipated.

Acknowledgements All work for this article took place outside of the author's official duty hours at the Social Security Administration.

Funding No funding was received for this literature review article.

\section{Compliance with Ethical Standards}

Conflict of interest The author has no conflict of interest to report for this literature review article.

Informed Consent Informed consent was not applicable for this literature review article. 
Research Involving Human and Animal Rights This literature review article does not contain any studies with human participants performed by any of the authors.

\section{References}

Abramowitz, J. (2017). Assisted reproductive technology and women's timing of marriage and childbearing. Journal of Family and Economic Issues, 38(1), 100-117. https://doi.org/10.1007/s1083 4-016-9485-4.

Ang, X. L. (2015). The effects of cash transfer fertility incentives and parental leave benefits on fertility and labor supply: Evidence from two natural experiments. Journal of Family and Economic Issues, 36(2), 263-288. https://doi.org/10.1007/s10834-014-9394-3.

Barbos, A., \& Milovanska-Farrington, S. (2019). The effect of maternity leave expansions on fertility intentions: Evidence from Switzerland. Journal of Family and Economic Issues, 40(3), 323-337. https://doi.org/10.1007/s10834-019-09609-3.

Barnett, A. E., \& Stum, M. S. (2012). Couples managing the risk of financing long-term care. Journal of Family and Economic Issues, 33(3), 363-375. https://doi.org/10.1007/s10834-012-9298-z.

Beauchamp, A. (2016). Abortion costs, separation, and non-marital childbearing. Journal of Family and Economic Issues, 37(2), 182-196. https://doi.org/10.1007/s10834-015-9473-0.

Berger, L. M., Collins, J., \& Cuesta, L. (2016). Household debt and adult depressive symptoms in the United States. Journal of Family and Economic Issues, 37(1), 42-57. https://doi.org/10.1007/ s10834-015-9443-6.

Bhatt, V. (2011). Adolescent alcohol use and intergenerational transfers: Evidence from micro data. Journal of Family and Economic Issues, 32(2), 296-307. https://doi.org/10.1007/s1083 4-010-9243-y.

Block, W. E. (2014). Toward a libertarian theory of evictionism. Journal of Family and Economic Issues, 35(2), 290-294. https://doi. org/10.1007/s10834-013-9361-4.

Cheng, K. W. (2011). The effect of contraceptive knowledge on fertility: The roles of mass media and social networks. Journal of Family and Economic Issues, 32(2), 257-267. https://doi.org/10.1007/ s10834-011-9248-1.

Cherry, R., \& Wang, C. (2015). Labor market conditions and US teen birth rates, 2001-2009. Journal of Family and Economic Issues, 36(3), 408-420. https://doi.org/10.1007/s10834-014-9402-7.

Chiswick, B. R., \& Mirtcheva, D. M. (2013). Religion and child health: religious affiliation, importance, and attendance and health status among American youth. Journal of Family and Economic Issues, 34(1), 120-140. https://doi.org/10.1007/s10834-012-9312-5.

Choi, H. (2011). Parents' health and adult children's subsequent working status: A perspective of intergenerational transfer and time allocation. Journal of Family and Economic Issues, 32(3), 493 507. https://doi.org/10.1007/s10834-010-9240-1.

Couch, K. A., Tamborini, C. R., \& Reznik, G. L. (2015). The long-term health implications of marital disruption: Divorce, work limits, and social security disability benefits among men. Demography, 52(5), 1487-1512. https://doi.org/10.1007/s13524-015-0424-z.

Delaney, J. J., \& Winters, J. V. (2014). Sinners or saints? Preachers' kids and risky health behaviors. Journal of Family and Economic Issues, 35(4), 464-476. https://doi.org/10.1007/s1083 4-013-9388-6.

Eshak, E. S. (2019). Mental health disorders and their relationship with work-family conflict in Upper Egypt. Journal of Family and Economic Issues, 40(4), 623-632. https://doi.org/10.1007/s1083 4-019-09633-3.
Giovanis, E., \& Ozdamar, O. (2019). A collective household labour supply model with disability: Evidence from Iraq. Journal of Family and Economic Issues, 40(2), 209-225. https://doi.org/10.1007/ s10834-018-9597-0.

Grossbard, S., \& Vernon, V. (2017). Common law marriage and teen birth. Journal of Family and Economic Issues, 38(1), 129-145. https://doi.org/10.1007/s10834-016-9511-6.

Gustavsen, G. W., Nayga, R. M., \& Wu, X. (2016). Effects of parental divorce on teenage children's risk behaviors: Incidence and persistence. Journal of Family and Economic Issues, 37(3), 474-487. https://doi.org/10.1007/s10834-015-9460-5.

Hofferth, S. L., \& Pinzon, A. M. (2011). Do nonresidential fathers' financial support and contact improve children's health? Journal of family and economic issues, 32(2), 280-295. https://doi. org/10.1007/s10834-010-9237-9.

Jung, H., \& Chang, C. (2016). Is mothers' work related to childhood weight changes in the United States? Journal of Family and Economic Issues, 37(4), 581-593. https://doi.org/10.1007/s1083 4-016-9484-5.

Kohn, J. L., \& Averett, S. L. (2014). Can't we just live together? New evidence on the effect of relationship status on health. Journal of Family and Economic Issues, 35(3), 295-312. https://doi. org/10.1007/s10834-013-9371-2.

Kusa, N. (2019). Financial compensation for intra-familial long-term care and childcare in Germany. Journal of Family and Economic Issues, 40(3), 352-366. https://doi.org/10.1007/s10834-01909622-6.

Lim, S. (2019). Mothers' nonstandard employment, family structure, and children's health insurance coverage. Journal of Family and Economic Issues, 40(2), 148-164. https://doi.org/10.1007/s1083 4-018-9596-1.

Mansour, F. (2018). Economic insecurity and fertility: Does income volatility impact the decision to remain a one-child family? Journal of Family and Economic Issues, 39(2), 243-257. https://doi. org/10.1007/s10834-017-9559-y.

Miller, G. E., \& Pylypchuk, Y. (2014). Marital status, spousal characteristics, and the use of preventive care. Journal of Family and Economic Issues, 35(3), 323-338. https://doi.org/10.1007/s1083 4-013-9375-y.

Mussida, C., \& Sciulli, D. (2019). Does the presence of a disabled person in the household affect the employment probabilities of cohabiting women? Evidence from Italy, France and the UK. Journal of Family and Economic Issues, 40(3), 338-351. https:// doi.org/10.1007/s10834-019-09612-8.

Penner, A. M., \& Dodge, K. A. (2019). Using administrative data for social science and policy. The Russell Sage Foundation Journal of the Social Sciences, 5(3), 1-18. https://doi.org/10.7758/ RSF.2019.5.3.01.

Richard, P. (2016). Children's mental disorders and their mothers' earnings: Implications for the affordable care act of 2010. Journal of Family and Economic Issues, 37(2), 156-171. https://doi. org/10.1007/s10834-016-9486-3.

Robinson, C. (2013). Younger siblings can be good for your health: An examination of spillover benefits from the supplemental nutrition program for women, infants, and children (WIC). Journal of Family and Economic Issues, 34(2), 172-184. https://doi.org/10.1007/ s10834-012-9325-0.

Shooshtari, S., Duncan, K. A., Roger, K., Fast, J., \& Han, J. (2017). Care-related out-of-pocket spending and caregiving consequences: Results from a canadian population-based study. Journal of Family and Economic Issues, 38(3), 405-420. https://doi.org/10.1007/ s10834-016-9516-1.

Shreffler, K. M., \& Johnson, D. R. (2013). Fertility intentions, career considerations and subsequent births: The moderating effects of women's work hours. Journal of Family and Economic Issues, 34(3), 285-295. https://doi.org/10.1007/s10834-012-9331-2. 
Suh, J. (2016). Measuring the "sandwich": Care for children and adults in the american time use survey 2003-2012. Journal of Family and Economic Issues, 37(2), 197-211. https://doi.org/10.1007/ s10834-016-9483-6.

Svynarenko, R., Zhang, Q., \& Kim, H. (2019). The financial burden of cancer: Financial ratio analysis. Journal of Family and Economic Issues, 40(2), 165-179. https://doi.org/10.1007/s1083 4-018-9587-2.

Tamborini, C. R., Reznik, G. L., \& Couch, K. A. (2016). Work disability among women: The role of divorce in a retrospective cohort study. Journal of Health and Social Behavior, 57(1), 98-117. https ://doi.org/10.1177/0022146515627849.

White-Means, S. I., \& Osmani, A. R. (2019). Job market prospects of breast vs. prostate cancer survivors in the US: A double hurdle model of ethnic disparities. Journal of Family and Economic Issues, 40(2), 282-304. https://doi.org/10.1007/s10834-01809607-x.

Zan, H., \& Scharff, R. L. (2018). The effects of children's health on mothers' employment. Journal of Family and Economic Issues, 39(2), 297-309. https://doi.org/10.1007/s10834-017-9552-5.
Publisher's Note Springer Nature remains neutral with regard to jurisdictional claims in published maps and institutional affiliations.

Christopher R. Tamborini is a Lecturer for the Department of Sociology at the Catholic University of America in Washington, DC. He is also a senior researcher in the Office of Research, Evaluation, and Statistics at the US Social Security Administration and a Research Associate at the Institute for Policy \& Social Research, University of Kansas. His research interests include aging and the life course, stratification, migration, work, family, and health. Recent work has appeared in the American Sociological Review, Demography, and the Journal of Health and Social Behavior. 